\title{
Metastatic medullary thyroid carcinoma presenting as ectopic Cushing's syndrome
}

\author{
Hannah E Forde1, Niamh Mehigan-Farrelly¹, Katie Ryan², Tom Moran³, Megan Greally, \\ Austin G Duffy ${ }^{5}$ and Maria M Byrne ${ }^{1}$ \\ 1Department of Endocrinology, ${ }^{2}$ Department of Pathology, ${ }^{3}$ Department of Otolaryngology, Mater Misericordiae \\ University Hospital, Dublin, Ireland, ^Department of Oncology, Mater Private Hospital, Dublin, Leinster, Ireland, and \\ 5Department of Oncology, Mater Misericordiae University Hospital, Dublin, Ireland
}

Correspondence should be addressed to $\mathrm{H}$ E Forde

Email

hannahforde@gmail.com

\section{Summary}

A 41-year-old male presented to the Emergency Department with a 6-month history of back and hip pain. Skeletal survey revealed bilateral pubic rami fractures and MRI of the spine demonstrated multiple thoracic and lumbar fractures. Secondary work up for osteoporosis was undertaken. There was no evidence of hyperparathyroidism and the patient was vitamin D replete. Testosterone (T) was low at $1.7 \mathrm{nmol} / \mathrm{L}(8.6-29.0)$ and gonadotrophins were undetectable. The patient failed a $1 \mathrm{mg}$ dexamethasone suppression test (DST) with a morning cortisol of $570 \mathrm{nmol} / \mathrm{L}(<50)$ and subsequently a low dose DST with a cortisol post $48 \mathrm{~h}$ of dexamethasone of $773 \mathrm{nmol} / \mathrm{L}(<50)$ and an elevated ACTH $98 \mathrm{ng} / \mathrm{L}$. A corticotropinreleasing factor (CRF) test suggested ectopic ACTH secretion. The patient was commenced on teriparatide for osteoporosis and metyrapone to control the hypercortisolaemia. A positron emission tomography (PET) scan to look for the source of ACTH secretion demonstrated right neck adenopathy. Biopsy and subsequent lymph node dissection were performed and histology revealed a metastatic neuroendocrine tumour. Immunostaining was positive for calcitonin and thyroid transcription factor 1 (TTF1). Serum calcitonin was also significantly elevated at $45264 \mathrm{ng} / \mathrm{L}(<10)$. The patient proceeded to a total thyroidectomy and left neck dissection. Histology confirmed a $7 \mathrm{~mm}$ medullary thyroid carcinoma (MTC). Post-operatively, the patient commenced vandetanib therapy and achieved a clinical and biochemical response. After approximately 18 months of vandetanib therapy, the patient developed recurrent disease in his neck. He is currently on LOXO-292 and is doing well 36 months post-diagnosis.

\section{Learning points:}

- Unexplained osteoporosis requires thorough investigation and the workup for secondary causes is not complete without excluding glucocorticoid excess.

- MTC should be considered when searching for sources of ectopic ACTH secretion.

- Resistance to tyrosine kinase inhibitors is well described with MTC and clinicians should have a low threshold for screening for recurrent disease.

\section{Background}

Medullary thyroid cancer (MTC) is a rare neuroendocrine tumour originating from the parafollicular ' $\mathrm{C}$ ' cells of the thyroid, and accounts for approximately $5 \%$ of thyroid neoplasms (1). Ectopic adrenocorticotropin (ACTH) secretion occurs in $<1 \%$ of MTC cases with approximately
50 cases reported in the literature to date (2). Cushing's syndrome in association with MTC presents significant management challenges and impacts patients' morbidity and mortality. However, RET inhibitors have provided some clinical benefit in the treatment of advanced 
MTC (3). Patients rarely present with symptoms or signs of a paraneoplastic syndrome associated with MTC. Here we report the case of a patient who presented with osteoporotic fractures secondary to ectopic ACTH secretion due to metastatic MTC.

\section{Case presentation}

A 41-year-old male presented to the Emergency Department with a 6-month history of back and hip pain. His past medical history was significant for previous lumbar spine fusion surgery 3 years prior. He had no significant family history. Medications included naproxen, esomeprazole, gabapentin, amitriptyline and oxycodone for pain. Clinical examination revealed a BMI of $33.1 \mathrm{~kg} / \mathrm{m}$, blood pressure 149/98 $\mathrm{mmHg}$, a plethoric facies, dorsal fat pad and central obesity with blue abdominal striae. Baseline laboratory investigations including a full blood count, renal, liver and bone profile were within normal limits.

\section{Investigation}

A skeletal survey revealed bilateral pubic rami fractures and compression fractures at T8 and L2 vertebrae. These were confirmed on MRI of the spine which also demonstrated fractures at T9, T10, T11, L4 and L5 in addition to rightsided neck adenopathy. Dual-energy X-ray absorptiometry (DEXA) scan confirmed osteoporosis with a T score of -2.0 S.D. at the lumbar spine and -3.2 s.D. at the femoral head.

Secondary work up for osteoporosis was completed. The patient had a corrected calcium of $2.31 \mathrm{mmol} / \mathrm{L}$ (2.20-2.60) and parathyroid hormone (PTH) $3.3 \mathrm{pmol} / \mathrm{L}$ (1.6-6.9). Vitamin D levels were sufficient at $45 \mathrm{nmol} / \mathrm{L}$ (>30). He had hypogonadotropic hypogonadism with a $\mathrm{T}$ $1.7 \mathrm{nmol} / \mathrm{L}$ (8.6-29.0) and undetectable gonadotrophins. His cortisol post $1 \mathrm{mg}$ DST was $570 \mathrm{nmol} / \mathrm{L}(<50)$ with an ACTH level of $97 \mathrm{ng} / \mathrm{L}$ (7-63). Hypercortisolaemia was confirmed on a low dose DST with a cortisol of 788 $\mathrm{nmol} / \mathrm{L}$ and ACTH of $98 \mathrm{ng} / \mathrm{L}$ (7-63) post $48 \mathrm{~h}$ of 6 hourly dexamethasone $(0.5 \mathrm{mg})$ administration. A corticotropinreleasing factor (CRF) test suggested ectopic ACTH secretion as there was no dose response increase in ACTH or cortisol post CRF injection (Time ${ }_{0}$ ACTH: $112.5 \mathrm{pg} / \mathrm{mL}$, cortisol 916 nmol/L; Time ${ }_{120}$ ACTH: 102.6 pg/mL, cortisol: $891 \mathrm{nmol} / \mathrm{L})$.

A positron emission tomography (PET) scan was performed to localise the source of ectopic ACTH. This demonstrated mildly hypermetabolic lymph nodes on the right side of the neck with no distal disease (Fig. 1). An octreotide scan confirmed tracer uptake in the right neck

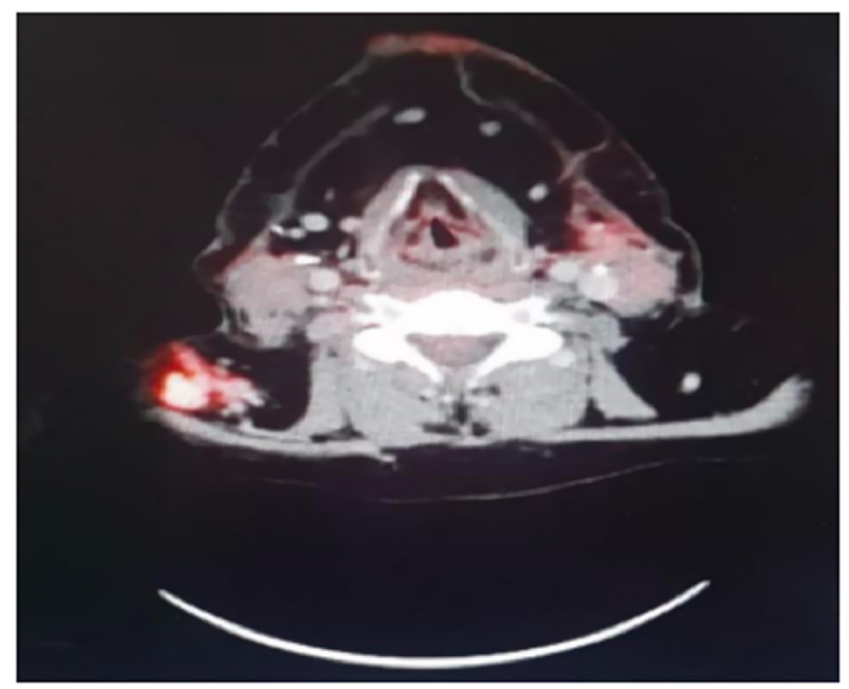

Figure 1

FDG avid adenopathy demonstrated in the right neck on PET scan.

nodes. The patient underwent a lymph node biopsy and histology was consistent with metastatic neuroendocrine tumour (NET). The patient subsequently underwent a right neck dissection. Histopathology revealed 28/44 lymph nodes positive for metastatic NET (Fig. 2A). Immunostaining was positive for calcitonin and thyroid transcription factor 1 (TTF1) and proliferation index was 10-15\% (Fig. 2B).

Serum calcitonin was subsequently measured and was significantly elevated at $45264 \mathrm{ng} / \mathrm{L}(<10)$. However, an ultrasound (US) thyroid performed to identify the source of the raised calcitonin demonstrated no concerning lesions.

\section{Treatment}

Whilst undergoing investigations, the patient was commenced on anti-hypertensives, teriparatide for osteoporosis and metyrapone to control the

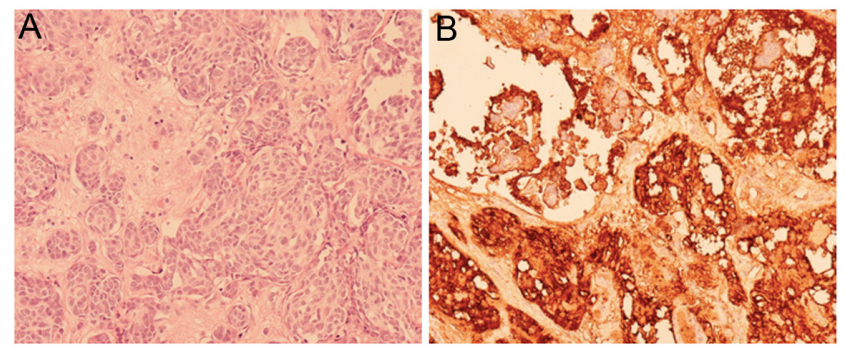

\section{Figure 2}

(A) Medullary thyroid lesion from neck dissection specimen at 40x; H\&E stain. (B) Immunohistochemistry demonstrating positive calcitonin staining. 
hypercortisolaemia. The metyrapone was commenced at an initial dose of $500 \mathrm{mg}$ three times daily to achieve a random cortisol of $250-350 \mathrm{nmol} / \mathrm{L}$. His maintenance metyrapone dose was $3750 \mathrm{mg} /$ day given in three divided doses. He was also commenced on octreotide LAR when histology confirmed a NET. Somatostatin analogues have also been shown to suppress ectopic ACTH secretion (4).

Following discussion at a multi-disciplinary team meeting, the patient proceeded to a total thyroidectomy and left neck dissection. Histology confirmed a $7 \mathrm{~mm}$ medullary thyroid carcinoma, a $3.5 \mathrm{~mm}$ papillary thyroid carcinoma and 39 lymph nodes were negative for disease. Immunostaining was positive for calcitonin, TTF1, synaptophysin and chromogranin. Somatic genetic testing on tumour sample from the right neck lymph node was positive for a RET mutation -c.2753T >C p.M1918TTier II variant associated with sporadic MTC. Germline testing from blood did not identify any familial genetic mutations.

\section{Outcome and follow-up}

Post-operatively, the patient remained hypercortisolaemic despite metyrapone therapy and his calcitonin levels rose to $86,222 \mathrm{ng} / \mathrm{L}$. He was commenced on vandetanib with subsequent dramatic improvement in cortisol and calcitonin levels (Figs 3 and 4). When serum cortisol and ACTH levels dropped as low as $198 \mathrm{nmol} / \mathrm{L}$ and $41 \mathrm{ng} / \mathrm{L}$ respectively, the patient was commenced on replacement hydrocortisone, in addition to metyrapone as part of a 'block and replace' regime. Metyrapone was stopped 3 months later and he subsequently discontinued all antihypertensive agents. The hydrocortisone was continued with regular monitoring of morning cortisol levels (measured before the morning dose of hydrocortisone, after withholding the evening dose of hydrocortisone

\section{ACTH and Cortisol trends over time}

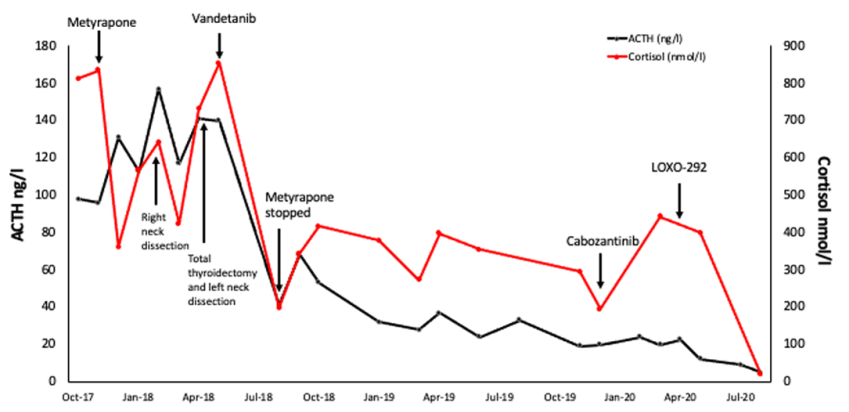

Figure 3

ACTH and cortisol responses to surgery and medical therapies.

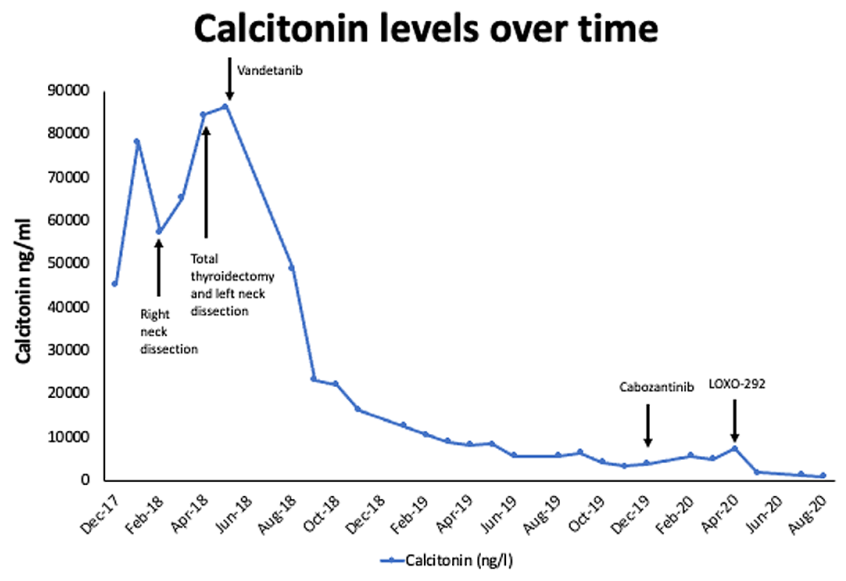

Figure 4

Calcitonin response to surgery and medical therapies.

the day prior). Despite an initial response to vandetanib therapy, 18 months post-commencing treatment, he noticed a mass in the right side of his neck. A PET scan demonstrated increased uptake and a subsequent biopsy confirmed recurrent metastatic medullary thyroid cancer. He commenced cabozantinib but this was discontinued 2 months later due to toxicity. Compassionate access to LOXO-292 - a novel RET inhibitor - was obtained and treatment implemented. His most recent imaging demonstrated a reduction in the size of the previous bulky lymph nodes with no new sites of disease. Six months on, he continues to do well. His calcitonin is $<1000 \mathrm{ng} / \mathrm{L}$. Recent cortisol and ACTH levels of $20 \mathrm{nmol} / \mathrm{L}$ and 5 $\mathrm{ng} / \mathrm{L}$, respectively reflect evidence of secondary adrenal insufficiency with resolution of ectopic ACTH secretion on LOXO-292. He completed 24 months of teriparatide and subsequently transitioned to alendronate. His repeat DEXA scan is pending. He continues to follow in oncology and endocrine clinic regularly.

\section{Discussion}

Cushing's syndrome secondary to ectopic ACTH secretion by MTC is rare, with Barbosa et al., reporting ectopic ACTH secretion in only $0.6 \%$ of MTC cases in their retrospective analysis of $>1600$ patients with MTC (5). Confirming that MTC is the source of ectopic ACTH secretion may be difficult as tumours do not always stain positively for ACTH on immunohistochemistry (6). Hence, the diagnosis is based on the presence of hypercortisolaemia with normal or high ACTH, which is not suppressed by high dose dexamethasone, the absence of a pituitary lesion on imaging and the parallel progression of MTC and Cushing's syndrome (5). For this patient, the CRF 
test was used, which has comparable diagnostic accuracy to the high dose dexamethasone suppression test in differentiating between pituitary and ectopic sources of ACTH secretion. MTC with paraneoplastic Cushing's syndrome has a poor prognosis with only $20 \%$ of patients surviving $>1$ year post-diagnosis (5). Despite the poor prognosis, the American thyroid association (ATA) recommends treatment for these patients as they are often symptomatic. Historical management has consisted of surgical debulking and anti-adrenal therapies. Urgent control of ectopic ACTH secretion is imperative as $50 \%$ of patients die from complications secondary to hypercortisolism (5). This patient was treated with metyrapone, a potent inhibitor of the steroidogenesis enzyme 11 1 -hydroxylase, in an effort to achieve rapid control of the hypercortisolism. Metyrapone has been shown to be effective for both short- and long-term control of hypercortisolaemia in Cushing's syndrome, though higher doses, are required in ectopic Cushing's syndrome (7). This patient was also treated with octreotide LAR. In MTC specifically, treatment with high doses of octreotide have been associated with improvements in biochemical parameters and symptoms but no reduction in tumour burden (4). However, as mentioned previously, somatostatin analogues can suppress ectopic ACTH and cortisol secretion, hence its use in this case. Despite treatment with medical therapy and extensive surgical resection of disease, this patients' calcitonin levels increased and high doses of metyrapone were required to control the hypercortisolaemia.

Recently, case reports suggest clinical and biochemical benefit with systemic TKI therapy. Vandetanib is a once daily oral inhibitor of RET kinase, vascular endothelial growth factor (VEGF) receptor, and epidermal growth factor receptor (EGFR) signalling, which in turn inhibits cell proliferation pathways (3). Vandetanib has demonstrated therapeutic efficacy in a phase III trial of patients with advanced MTC (3). Vandetanib has also been associated with positive outcomes in patients with MTC related ectopic Cushing's syndrome in case reports. Baudry et al., reported the case of a 58-year-old male with MTC and paraneoplastic Cushing's syndrome resistant to metyrapone, mitotane and somatostatin analogues and ketoconazole (8). A trial of vandetanib resulted in a rapid reduction in both cortisol and calcitonin levels but no reduction in tumour size, suggesting a direct potent anti-secretory effect of this drug (8). Unfortunately, however, MTC resistance to TKIs is well documented, though how long before acquired resistance occurs is less well established. Our patient achieved excellent clinical and biochemical response but only for 18 months on vandetanib. Cabozantinib is another TKI that is used in the treatment of MTC was poorly tolerated by this patient secondary to nausea and vomiting. Indeed, adverse events associated with cabozantinib are common, and have led to treatment discontinuation in up to $16 \%$ of patients in one large phase III trial (9). LOXO-292 is a highly selective RET inhibitor with activity across known oncogenic RET fusions and mutations (10). In the LIBRETTO-001 phase 1 clinical trial, LOXO-292 demonstrated $45 \%$ overall response rates in RET-mutant MTC with a favourable safety and tolerability profile (10). Furthermore, its antitumour activity was independent of exposure to prior therapy and hence may be promising therapeutic agent for patients with metastatic MTC. This is evident in the aforementioned case, as this patient had a dramatic clinical and biochemical response to LOXO-292 despite acquired resistance to vandetanib after 18 months of treatment.

Our patient first presented with symptoms related to osteoporosis which prompted further investigations eventually leading to the diagnosis of MTC with ectopic ACTH secretion. His osteoporosis was treated with teriparatide which stimulates osteoblastogenesis and inhibits osteoblast apoptosis thereby counteracting two of key mechanisms by which glucocorticoids promote bone loss (11). Teriparatide is superior to bisphosphonates for increasing bone mineral density at both the hip and the spine in glucocorticoid-induced osteoporosis (11). Interestingly, small studies and case reports also suggest spontaneous recovery of bone mass occurs after the cure of endogenous hypercortisolism $(12,13)$.

In summary, MTC-related Cushing's syndrome is a rare complication of this aggressive tumour and presents significant diagnostic and management challenges for clinicians and patients, respectively. Symptoms and signs of hypercortisolism may precede the diagnosis of MTC and multiple agents may be required to achieve disease control. Newer RET inhibitors are promising but longterm follow-up data are lacking.

Declaration of interest

The authors declare that there is no conflict of interest that could be perceived as prejudicing the impartiality of the research reported.

\section{Funding}

This research did not receive any specific grant from any funding agency in the public, commercial or not-for-profit sector. 


\section{Patient consent}

Written consent has been obtained from the patient.

\section{Author contribution statement}

$\mathrm{H} F$ conducted the chart review and prepared the first draft of the manuscript. N M F contributed to the preparation of the manuscript. $\mathrm{K}$ Ryan contributed to the preparation of the figures for the manuscript. TM, M G and A D contributed to the final draft of the manuscript. M B collected data and contributed to the preparation of the manuscript.

\section{References}

1 Cipri C, Vescini F, Torresan F, Pennelli G, Pelizzo MR, Triggiani V, Guastamacchia E \& Grimaldi F. An unusual case of medullary thyroid carcinoma and a revision of current literature. Endocrine, Metabolic and Immune Disorders Drug Targets 201919 226-229. (https://doi.org/ $10.2174 / 1871530319666181220165350)$

2 Matheny LN, Wilson JR \& Baum HB. Ectopic ACTH production leading to diagnosis of underlying medullary thyroid carcinoma. Journal of Investigative Medicine High Impact Case Reports 20164 2324709616643989. (https://doi.org/10.1177/2324709616643989)

3 Wells Jr SA, Robinson BG, Gagel RF, Dralle H, Fagin JA, Santoro M, Baudin E, Elisei R, Jarzab B, Vasselli JR, et al. Vandetanib in patients with locally advanced or metastatic medullary thyroid cancer: a randomized, double-blind phase III trial. Journal of Clinical Oncology 201230 134-141. (https://doi.org/10.1200/JCO.2011.35.5040)

4 de Herder WW, Van der Lely AJ \& Lamberts SW. Somatostatin analogue treatment of neuroendocrine tumours. Postgraduate Medical Journal 199672 403-408. (https://doi.org/10.1136/pgmj.72.849.403)

5 Barbosa SL, Rodien P, Leboulleux S, Niccoli-Sire P, Kraimps JL, Caron P, Archambeaud-Mouveroux F, Conte-Devolx B, Rohmer V \& Groupe d'Etude des Tumeurs Endocrines. Ectopic adrenocorticotropic hormone-syndrome in medullary carcinoma of the thyroid: a retrospective analysis and review of the literature. Thyroid 200515 618-623. (https://doi.org/10.1089/thy.2005.15.618)

6 Wijewardene AA, Glastras SJ, Learoyd DL, Robinson BG \& Tsang VHM. ACTH-secreting medullary thyroid cancer: a case series. Endocrinology, Diabetes and Metabolism Case Reports 20172017 160110. (https://doi.org/10.1530/EDM-16-0110)

7 Daniel E, Aylwin S, Mustafa O, Ball S, Munir A, Boelaert K, Chortis V, Cuthbertson DJ, Daousi C, Rajeev SP, et al. Effectiveness of metyrapone in treating cushing's syndrome: a retrospective multicenter study in 195 patients. Journal of Clinical Endocrinology and Metabolism 2015100 4146-4154. (https://doi.org/10.1210/jc.20152616)

8 Baudry C, Paepegaey AC \& Groussin L. Reversal of Cushing's syndrome by vandetanib in medullary thyroid carcinoma. New England Journal of Medicine 2013369 584-586. (https://doi. org/10.1056/NEJMc1301428)

9 Elisei R, Schlumberger MJ, Müller SP, Schöffski P, Brose MS, Shah MH, Licitra L, Jarzab B, Medvedev V, Kreissl MC, et al. Cabozantinib in progressive medullary thyroid cancer. Journal of Clinical Oncology 201331 3639-3646. (https://doi.org/10.1200/JCO.2012.48.4659)

10 Drilon A, Subbiah V, Oxnard GR, Bauer TM, Velcheti V, Lakhani NJ, Besse B, Park K, Patel JD, Cabanillas ME, et al. A phase 1 study of LOXO-292, a potent and highly selective RET inhibitor, in patients with RET-altered cancer. Journal of Clinical Oncology 201836102. (https://doi.org/10.1200/JCO.2018.36.15 suppl.102)

11 Saag KG, Shane E, Boonen S, Marín F, Donley DW, Taylor KA, Dalsky GP \& Marcus R. Teriparatide or alendronate in glucocorticoidinduced osteoporosis. New England Journal of Medicine $2007 \mathbf{3 5 7}$ 2028-2039. (https://doi.org/10.1056/NEJMoa071408)

12 Randazzo ME, Grossrubatscher E, Ciaramella PD, Vanzulli A \& Loli P. Spontaneous recovery of bone mass after cure of endogenous hypercortisolism. Pituitary 201215 193-201. (https://doi. org/10.1007/s11102-011-0306-3)

13 Dobnig H, Stepan V, Leb G, Wolf G, Buchfelder M \& Krejs GJ. Recovery from severe osteoporosis following cure from ectopic ACTH syndrome caused by an appendix carcinoid. Journal of Internal Medicine 1996239 365-369. (https://doi.org/10.1046/j.13652796.1996.416763000.x)

Received in final form 26 February 2021

Accepted 30 March 2021 